\title{
MEDICINA VETERINÁRIA: COMO ESCREVER UM RELATO DE CASO CLÍNICO-CIRÚRGICO?
}

\author{
Veterinary Medicine: How to Write a Clinical and \\ Surgical Case Report?
}

Rüdiger Daniel Ollhoff ${ }^{1}$

\section{Resumo}

A publicação de relatos de casos clínicos e cirúrgicos constitui o primeiro passo para estudantes de Medicina Veterinária e profissionais autônomos, em princípio de carreira, iniciarem-se na comunicação científica por escrito. Descrevem-se os principais itens a serem abordados e os cuidados a serem tomados desde a escolha do caso e da revista até os últimos passos para o envio do trabalho pronto. Objetiva-se, com este artigo, demonstrar que a escrita de relatos de caso é uma habilidade que pode ser aprendida, incentivando-se as futuras gerações a buscarem a comunicação por escrito.

Palavras-chave: Medicina Veterinánia; Comunicação; Relato de caso.

\section{Abstract:}

The publication of clinical and surgical case reports constitutes the first step for veterinary students and clinicians at the start of their career to begin write scientific communications. The main aspects to be verified and cared about, since the choice of the journal until the submitting of the written article are described. This article intends to demonstrate that the skill to write case reports can be learned, encouraging future generations to reach for and apply the written communication.

Keywords: Veterinary medicine; Communication; Case report.

1 Médico Veterinário, Professor Titular de Semiologia, Clínica médica e cirúrgica de ruminantes da PUCPR BR 376, km 14 Cx. Postal 129 - CEP: 83010-500 - São José dos Pinhais - PR - Brasil.

E-mail: ollhoff@rla01.pucpr.br 


\section{Introdução}

O desenvolvimento de uma carreira na área das ciências agrárias e da saúde exige cada vez mais que o profissional seja um bom comunicador. Esta habilidade deve ser aprendida não somente em sua forma verbal, mas também escrita. Apesar da existência de uma grande variedade de literatura visando a ensinar o ofício da comunicação escrita, não se encontram facilmente publicações voltadas especificamente a um público médico veterinário (POENICKE 1988; DAY 1990; MCKOWN 1992; SOVA 1998; REY 2000). Precisamente a descrição de casos, uma maneira de o médico veterinário autônomo iniciar-se na comunicação científica, somente encontrou interesse na literatura especializada recentemente (MISCHKE, 2003).O presente trabalho visa a instruir médicos veterinários autônomos e também graduandos em medicina veterinária a como publicar casos. Objetiva-se fornecer as ferramentas necessárias aos novos autores respondendo às seguintes perguntas:

- Como decidir se o caso é publicável?

- Qual a melhor forma de publicação?

- Como descrever o caso?

\section{Como decidir se o caso é publicável?}

A maioria dos veterinários atuantes nas áreas clínica e cirúrgica se depara com casos que aparentam qualidade para publicação. Atualmente, na medicina veterinária, dificilmente obter-se-á a chance de descrever uma enfermidade completamente desconhecida. No entanto, existe uma miríade de enfermidades raras ou evoluções incomuns nas quais uma descrição detalhada é valiosa. Isto vale de igual forma para os casos em que ocorrem complicações inesperadas e pouco comuns ou em que se utilizam condutas terapêuticas não convencionais. Combinações desconhecidas de diferentes estados patológicos e estratégias terapêuticas inovadoras também são publicáveis.

Fundamental é que o conteúdo do caso descrito transmita uma mensagem com significado particular ao leitor. Esta mensagem sempre terá um intuito informativo e esclarecedor. Por exemplo, o relato ressalta os benefícios e riscos de um determinado tratamento ou conscientiza o leitor sobre a ocorrência de uma doença rara.
Para averiguar o quanto o próprio caso supre os critérios postos, deverá ser realizado um levantamento da literatura existente. As bibliotecas das universidades e institutos de pesquisa possuem sistemas de busca informatizados da literatura existente no acervo e facilitam o acesso à literatura não disponível de imediato. A Internet oferece diferentes sistemas de busca (Exemplos: www.scielo.br; www.animalscience.com), muitos dos quais, porém, são pagos. A discussão com colegas e apresentações em simpósios e congressos também são úteis para averiguar o impacto prévio do caso. Deslizes na técnica, erros de diagnóstico ou complicações na conduta terapêutica são mais interessantes e elucidativos para colegas na prática do que a simples descrição de um caso raro. Apesar disto, não são os mais freqüentemente vistos, pois podem - dependendo das circunstâncias - prejudicar a reputação do colega. Por este motivo, há uma necessidade de se incentivar os colegas autônomos a relatar estes casos.

\section{Qual a melhor forma de publicação?}

Antes de redigir o relato do caso clínico ou cirúrgico, deverá ser escolhido o periódico e a forma de publicação. Relatos de caso são publicados exclusivamente em revistas da área técnica, nunca em revistas de criadores ou voltados para um público leigo. A Internet oferece a possibilidade de se publicar em revistas que disponibilizam o artigo na rede sob a forma de hipertexto ou em endereços eletrônicos (sites) de associações de classe. A forma mais usual, porém, ainda consiste na publicação em um periódico da área veterinária. Para uma primeira publicação, facilita a escolha por uma revista que o próprio autor costuma ler. Esta leitura faz com que se crie uma percepção do que é considerado interessante pelos redatores da revista e seu público. As revistas indexadas voltadas a um público de veterinários mais abrangentes como a Revista do Conselho Federal de Medicina Veterinária, a Revista de Educação Continuada do CRMV de São Paulo e revistas voltadas ao autônomo clínico na área de pequenos animais de estimação como a Clínica Veterinária e a Medvep somente para citar algumas, publicam relatos de casos. Outras revistas veterinárias mais voltadas a um público científico que abrange diversas especialidades com um comitê editorial atuante como 
a Archives of Veterinary Science e a Arquivos de ciências veterinárias e zoologia da Unipar publicam relatos de caso. Revistas especializadas, como, por exemplo, a Veterinary Pathology ou a Veterinary Dermatology também publicam casos, desde que de interesse específico ao público-alvo de leitores destas revistas. A publicação de relatos de caso mantém as revistas atrativas principalmente para com o médico veterinário autônomo, com atividade em clínicas de pequenos animais, consultorias ou cooperativas. Uma mensagem de interesse ao leitor e o inusitado do caso são fundamentais. Nem sempre as revistas condicionam a publicação do caso à não divulgação anterior, por exemplo, em congressos da área.

As revistas em papel possuem a vantagem de ainda gozarem de uma maior aceitação pelo público em geral, em conseqüência de uma maior versatilidade e confiabilidade, decorrentes da independência do uso de energia elétrica e da não suscetibilidade a panes do mundo informatizado (vírus, etc.).

Vantajosa é a escolha de revistas que possuam corpo editorial e à qual os artigos submetidos são revisados pelos pares, o que é garantia de uma qualidade superior. Uma negativa em uma das revistas não deverá impedir o autor, considerando as críticas dos assessores/relatores, a enviar o relato para uma outra revista.

\section{Como descrever o caso?}

Uma vez convicto do potencial do caso a ser relatado, isto é, que irá suscitar interesse suficiente dos colegas, é imprescindível apresentar a mensagem ao leitor de uma maneira igualmente a despertar a curiosidade. Para redigir o manuscrito no estilo da revista prevista para publicação, deverão ser estudados as instruções para os autores, contidas mormente no final da revista, de maneira detalhada. Poderá ser útil nortear-se por alguns relatos atuais apresentados na revista.

Todas as regras válidas em outras publicações científicas deverão ser consideradas também no relato de caso. A linguagem deverá ser clara e precisa. O objetivo principal do relato de caso é possibilitar a seu leitor em sua atividade prática reconhecer um problema semelhante e solucioná-lo. Na redação de um relato de caso, inicialmente, anota-se a evolução do caso, então a discussão deverá ser desenvolvida e os demais componentes adicionados.

\section{Título}

O título é de suma importância, pois diversos leitores da revista, após uma prévia passagem pelos títulos, lêem somente alguns artigos por completo. O título ideal deveria ser curto, descritivo e chamativo. Títulos descritivos muito compridos (Exemplo: Sucesso de uma terapia imunomoduladora com sangue total na rhabditiose aunicular de uma vaca girolanda) podem levar o leitor à impressão que todas as informações essenciais foram transmitidas, evitando um aprofundamento da leitura.

\section{Autores}

Todos os autores que contribuíram de maneira substancial ao diagnóstico ou terapia do paciente, considerando-se que os aspectos raros do caso deverão ser citados. Multiplicam-se as publicações com um número abusivamente grande de autores em que o bom senso parece não ter sido incluído.

\section{Introdução}

Freqüentemente os relatos de caso recebem uma pequena introdução, situando o caso diante da literatura conhecida e disponível e chamando atenção para sua importância. No entanto, não há necessidade de uma introdução, iniciandose com a descrição do caso em si. Na segunda opção, deverá se realizar a contraposição do caso em relação à literatura pesquisada dentro da discussão.

\section{Resumo}

Na dependência da revista ou formato da revista a ser publicado, um resumo poderá ser desnecessário. Nos demais casos, o resumo deverá ser curto, sem entrar em um detalhamento profundo e abordar a relevância do caso descrito. Uma frase contendo qual foi a conclusão do caso é um bom final do resumo. 


\section{Palavras-chave}

As palavras-chave solicitadas pelo formato da revista objetivam correlacionar o artigo no Index Veterinarius ou Index Medicus a uma determinada categoria. Portanto, as palavras-chave poderão se orientar pelos catálogos de palavras-chave (Thesaurus) destes índices.

\section{Material e métodos}

Quando se utilizam métodos especiais e dispendiosos, a sua descrição precisa auxiliará o entendimento e deverá ser realizado em separado, necessariamente antes da casuística propriamente dita e após uma pequena introdução.

\section{Casuística}

A casuística como elemento central do manuscrito orientar-se-á pelas regras do trabalho clínico, ou seja, é necessária a apresentação em ordem cronológica, desde a identificação do paciente, histórico, anamnese, exame clínico e eventuais exames complementares antes de se chegar ao diagnóstico, possíveis diagnósticos diferenciais, tratamento e evolução do caso. Especial valor possuem o como da construção do diagnóstico e o tipo e momento temporal dos tratamentos instituídos. Os achados essenciais positivos para a solução do caso deverão ser detalhados e apresentados integralmente. Somente "achados negativos" relevantes deverão ser relatados, para não abafar a essência do caso em um mar de informações irrelevantes.

Para a descrição de achados específicos, figuras podem ser de grande valia, na forma de fotografias do paciente, esquemas cirúrgicos, intervenções terapêuticas, entre outras. A evolução de sinais clínicos e laboratoriais poderá ser ilustrada por gráficos e tabelas. Os valores contidos em tabelas e gráficos deverão constar no texto somente como exemplos, não mais em sua totalidade.

\section{Discussão}

A discussão deverá fornecer explicações ao leitor para os achados raros e como e por que determinadas decisões na conduta do caso foram tomadas. Os principais ensinamentos e conclusões para o leitor deverão ser trabalhados de maneira clara. Eventuais questionamentos do leitor deverão ser premeditados e respondidos. Um bom relato de caso deverá fornecer elementos ao colega leitor de como ele deveria tratar de um caso semelhante. A literatura citada deverá se restringir aos trabalhos que estão relacionados diretamente à especificidade do caso. Para a discussão, é relevante citar os trabalhos que corroboram ou contradizem a própria experiência, decisões ou conclusões. Como nos demais artigos científicos, deverá se dar preferência - dentro de um contexto de disponibilidade - aos trabalhos publicados em periódicos, evitando-se a citação de livros texto, a não ser que um tratamento padrão descrito em um destes livros tenha levado a complicações.

\section{Últimos passos da confecção do manuscrito}

Após a primeira conclusão do manuscrito, é vantajoso mantê-lo por alguns dias "descansando", antes que se faça uma releitura do trabalho com eventuais correções ou alterações. A leitura crítica por um colega que desconhece o caso é de excepcional ajuda, pois os apontamentos deste servirão para esclarecer os fatos e melhorar a interpretação deles. No controle final deverá estar incluída a manutenção do estilo da revista à qual o trabalho será submetido, no que tange, por exemplo, a forma de citação da literatura, as palavras-chave, título, entre outros. A submissão do caso é realizada com o envio do trabalho em cópias impressas (de duas a três) e na forma eletrônica (disquete, $C D$ ), anexos a uma correspondência ao editor ou redator da revista solicitando a sua publicação.

A melhor garantia da publicação de um relato de caso é possuir um caso inusitado e realizar uma apresentação interessante e de fácil leitura. 


\section{Referências}

DAY, R. A. Cómo escribir y publicar trabajos científicos. Publicación Científica 526 Washington: Organización Mundial de la salud: Organización Panamericana de la Salud,1990. p. 214.

MCKOWN, D. L. Writing forcareergrowth. In: IEEE Engineers Guide to Business. New York: IEEE, 1992. p. 4-12.

MISCHKE, R. Wie schreibe ich einen Fallbericht ? Der Praktische Tierarzt 84, n. 1, p. 21-23. 2003.
POENICKE, K. Wie verfasst man wissenschaftliche Arbeiten ? Ein Leitfaden vom ersten Studiensemester bis zur Promotion. Dudentaschenbücher. 2 ed. Zürich: Dudenverlag, 1988. Band 21. p. 216.

REY, L Planejar e redigir trabalhos científicos. São Paulo,SP: Edgard Blücher, 2000. p. 318.

SOVA, D. B. How to write articles for newspapers and magazines. New York: Macmillan, 1998. p. 119. 